\title{
Implementation of OCPP Protocol for Electric Vehicle Applications
}

\author{
Thota Venkata Pruthvi ${ }^{1}$, Niladri Dutta ${ }^{2}$, Phaneendra Babu Bobba $^{3 *}$, B Sai Vasudeva ${ }^{4}$ \\ ${ }^{1}$ VLSI Engineer, HCL Technologies, Chennai, India tv166@snu.edu.in \\ ${ }^{2}$ Associate System Engineer, IBM India Pvt. Ltd., Bangalore, India nd933@snu.edu.in \\ ${ }^{3}$ Dept. of Electrical\& Engineering, GRIET, Hyderabad, Telangana., India bobbaphani@griet.ac.in \\ ${ }^{4}$ Dept. of Electrical \& Electronics Engineering, GRIET, Hyderabad, Telangana., India saivasudeva.b@gmail.com
}

\begin{abstract}
The ability of the software and hardware systems to interchange information is a key factor for the success of the electric vehicle industry. Standards have been developed and are in use to ensure base level interoperability of the front-end communication and signaling processes for smart charging between electric vehicles and charge stations. The Open Charge Alliance (OCA), a group of European industries, have developed an open source common back-end protocol, called Open Charge Point Protocol (OCPP), for charging stations to reduce and secure overall investment costs. OCPP intends to enable grid services based on smart charging. In this paper the authors provide a review of the functionalities OCPP offers and how it can be used in the electrical vehicle-charging infrastructure.
\end{abstract}

\section{Introduction}

For the budding EV charging market, assortment is something worth being thankful for. Rivalry drives down expenses and raise mechanical upgrades. Today, government or private charging suppliers look over a large number of charging station makers and system framework merchants. This wide decision brings up the issue of interoperability, or, as it were, the capacity of every EV accusing station to impart of a focal framework, paying little heed to the maker or IT back-

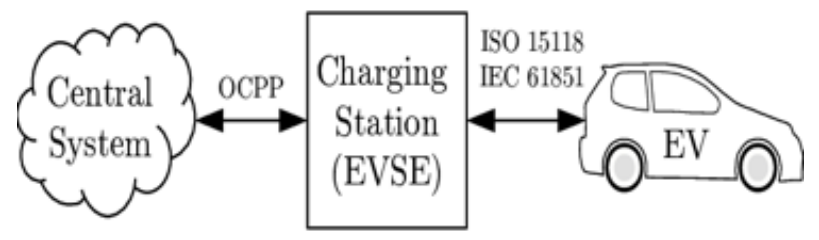

Fig. 1. Electric vehicle interface standards. [1]

end seller. That is the place the Open Charge Point Protocol (OCPP) comes in.

Keep in mind when you initially purchased a mobile phone and it just worked with one transporter? You were secured to their administration bundle regardless. The Open Charge Point Protocol (OCPP) ensures that you can switch among equipment and programming suppliers without your speculation getting to be old. It's as basic as exchanging the SIM card in your telephone. The objective of OCPP is to empower a genuinely interoperable EV charging foundation - a framework that is versatile and simple to work both for EV drivers and system administrators. With the OCPP, clients can

\footnotetext{
* Corresponding author
}

incorporate charging stations from a few merchants into a similar IT back-end framework. They can likewise choose the most fitting charging station vendor(s) and the most proper IT back-end provider freely.

OCPP was advanced by the Open Charge Alliance and has turned into an inexorably well-known convention and a true standard in excess of 50 nations and over $10,000+$ charging stations. In contrast to restrictive correspondence conventions, OCPP is open and not associated with any permitting expense or prerequisite, making it simple to receive. Embraced by many charge point sellers and focal framework providers, OCPPconsistence is presently turning into an "absolute necessity have" prerequisite among speculators. They consider it to be an approach to keep their foundation merchant nonpartisan and to decrease costs.

Open Charge Alliance discharged another sort of convention called OSCP (Open Smart Charging Protocol) This convention can be utilized to impart a 24hour forecast of the neighborhood accessible ability to the Charge Spot Operator. The Service Provider will fit the charging profiles of the electrical vehicles inside the

Table 1. Electric Vehicle Connector Standards

\begin{tabular}{|c|c|c|c|}
\hline & USA & Europe & China/ India \\
\hline $\begin{array}{l}\text { Alternating } \\
\text { current } \\
\text { (AC) }\end{array}$ & $\begin{array}{l}\mathrm{SAE} \\
\mathrm{J} 1772 / \mathrm{IEC} \\
62196-2\end{array}$ & IEC 62196-2 & GB Part 2 \\
\hline $\begin{array}{l}\text { Direct } \\
\text { current } \\
\text { (DC) }\end{array}$ & IEC 62196-3 & IEC 62196-3 & $\begin{array}{l}\text { GB Part 2/ } \\
\text { IEC 62196-3 }\end{array}$ \\
\hline $\begin{array}{l}\text { Combined } \\
\text { AC/DC }\end{array}$ & $\begin{array}{l}\text { SAE } \\
\text { J1772/IEC } \\
62196-3\end{array}$ & IEC 62196-3 & \\
\hline
\end{tabular}


limits of the accessible limit. It is a protocol between charge point management system and energy management system of the site owner.

\section{Charging Infrastructure}

Typically, the Charging Infrastructure consists of Electric Vehicle (EV), Charging Station, Charging Station Management system (CSMS) as Shown in Fig I. The Charging Station is the physical framework where an EV can be charged. A Charging Station has at least one Electric Vehicle Supply Equipment (EVSEs) [2]. An EVSE is considered as an autonomously worked and oversaw some portion of the Charging Station that can convey vitality to one EV at any given moment. EVSE needs to speak with Battery Management System (BMS) of battery pack in EV, to empower it to charge at right rate for keeping up SOH of batteries. Physical layer for this correspondence can be Power Line Communication (PLC) or Controller Area Network (CAN), CAN is ordinarily utilized by vehicle producers in India. There

Table 2. Commonly used terms

\begin{tabular}{|l|l|}
\hline Term & Meaning \\
\hline Charging Station & $\begin{array}{l}\text { The Charging Station is the } \\
\text { physical system where an EV } \\
\text { can be charged. A Charging } \\
\text { Station has one or more EVSEs. }\end{array}$ \\
\hline $\begin{array}{l}\text { Charging Station } \\
\text { Management }\end{array}$ & $\begin{array}{l}\text { Charging Station Management } \\
\text { System: manages Charging } \\
\text { Stations and has the information } \\
\text { for authorizing Users for using } \\
\text { its Charging Stations. }\end{array}$ \\
\hline $\begin{array}{l}\text { Electric Vehicle } \\
\text { Supply Equipment } \\
\text { (EVSE) }\end{array}$ & $\begin{array}{l}\text { An EVSE is considered as an } \\
\text { independently operated and } \\
\text { managed part of the Charging } \\
\text { Station that can deliver energy to } \\
\text { one EV at a time. }\end{array}$ \\
\hline CSO & Charging Station Operator \\
\hline EV & Electric Vehicle \\
\hline RFID & Radio-Frequency Identification \\
\hline
\end{tabular}

are different Electric Vehicle Connector Standards with respect to different countries, some of them are mentioned in Table II.

\section{OCPP Version History}

There are mainly three different versions of OCPP from the time of its first release. They are OCPP 1.5, OCPP 1.6 and OCPP 2.0 respectively.

\subsection{OCPP 1.2}

This version of OCPP is similar to OCPP 1.5, with fewer functionalities.

\subsection{OCPP 1.5}

There are 25 Operations described in OCPP 1.5[5], 10 are initiated by Charging Station and 15 are initiated by the Central management system. Authorize, Boot Notification, Data Transfer, Diagnostics Status Notification, Firmware Status Notification, Heartbeat, Meter Values, Start Transaction, Status Notification, Stop Transaction, are Initiated by charge point and Cancel Reservation, Change Availability, Change Configuration, Clear Cache, Data Transfer, Get Configuration, Get Diagnostics, Get Local List Version, Remote Start Transaction, Remote Stop Transaction, Reserve Now, Reset, Send Local List, Unlock Connector, Update Firmware are initiated by the central system.

\subsection{OCPP 1.6}

This adjustment of OCPP uses SOAP Framework to send messages between sections over the Internet. The upside of SOAP is that the workplaces for sending and tolerating messages are anchored by the standard [6]. This makes quick utilization possible. substance of a SOAP message are pulled in up according to the Extensible Markup Language (XML) standard. This dialect is identified with the HTML. Notwithstanding composed content, XML messages may likewise contain pictures and executable code. The enormous favorable position is that the messages are sent in decipherable content.

\subsection{OCPP 2.0}

OCPP 2.0 is the most recent adaptation discharged in April 2018, it contains a great deal of new highlights canvassed in 116 use cases. OCPP 2.0 [7] just backings JSON. There are many included and enhanced functionalities like Device Management, Improved Transaction taking care of, Added Security, Added Smart Charging functionalities, Support for 15118, Display and informing support, and numerous extra upgrades asked for by the EV charging network. without title.

\section{Implementation of OCPP 2.0}

The OCPP protocol describes many use cases and messages. There are 16 Functional Blocks with one or more use cases in each of them. Out of these only some are needed to implement a basic Charging Station or CSMS. Table III lists messages that are typically implemented to deliver basic functionality for an OCPP managed Charging Station.

\subsection{Booting, Configuration and Resetting a Charging Station}

Booting, configuring and resetting of the Charging Station Functionalities goes under the Provisioning Functional block of OCPP 2.0. This Functional Block depicts every one of the functionalities that assistance a CSO arrangement their Charging Stations, enabling them to validate certifications and recover setup data from these Charging Stations over a system. Also, it comprises of the capacity to make changes to the Charging System configuration, as well. There are 12 use cases which gone under this functional block, among 
them are- Cold Boot Charging Station, Cold Boot Charging Station - Pending, Cold Boot Charging StationRejected, Offline Behavior Idle Charging Station, Set Variables, Get Variables, Get Base Report, ResetWithout Ongoing Transaction and Reset-With Ongoing Transaction - are the mandatory use cases for the essential execution of OCPP 2.0.

\subsection{Authorization options}

This functionality comes under the Authorization Functional block of OCPP 2.0, This functional block describes all the authorization-related functionalities, it contains different ways of authorizing a user (online and/or offline), the AuthorizeRequest message handling, and the Authorization Cache functionality, etc. When a user wishes to unplug the electric vehicle from the Charging Station, the Charging Station needs to verify that the user is either the one that initiated the charging or that the user is in the same group and thus allowed to terminate the charging. Once authorized, the Charging Station informs the CSMS that the charging has been stopped. This functional block has 16 Use Cases in which any one of these - EV Driver Authorization using RFID, Authorization using a start button and Authorization using PIN-code are mandatory for the basic implementation.

\subsection{Transaction mechanism}

This functionality comes under Transactions Functional block of OCPP 2.0 and it describes the OCPP transaction related functionalities. Transactions can be started or stopped on the Charging Station with only one active transaction on an EVSE, at a time. This functional block has 15 use cases - Start Transaction Options, Start Transaction-Cable Plugin First, Start TransactionIdToken First, Start Transaction-Id not Accepted, Stop Transaction Options, Transaction locally stopped by IdToken, Transaction stopped while Charging Station is offline one of when cable disconnected on EV-side: Stop Transaction and When cable disconnected on EV-side: Suspend Transaction, Connection Loss During Transaction, Inform CSMS of an Offline Occurred Transaction and Transaction related message not accepted by CSMS are mandatory for basic implementation.

\subsection{Availability}

This functionality goes under Availability Functional block of OCPP 2.0. It indicates how the Charging Station can educate the CSMS of its present accessibility for beginning new exchanges. It is vital for the CSO to know whether a Charging Station is accessible for EVs to be charged, with the goal that they can advise EV drivers whether the Charging Station is accessible for use. Therefore, the Charging Station ought to consistently send any status changes of itself or any of its EVSEs to the CSMS.

This transaction status is exceptionally helpful for an EV Driver when he encounters issues amid charging. At the point when a blame is recognized by the Charging Station it can communicate something specific telling the CSMS about the fault. At the point when the CSO needs the Charging Station to never again begin new exchanges, it can change the accessibility. For instance: they have to do upkeep on the Charging Station, and hence they don't need the Charging Station to be being used. The CSO can likewise change the accessibility for at least one EVSEs. For instance: A client calls, whining about a broken EVSE on the Charging Station. The CSO would then be able to set the Connector to inaccessible, making it impossible for an EV Driver to utilize that Connector. Clearly, with a direction from the CSMS it is likewise conceivable to make the Charging Station or a Connector accessible once more.

This functional block has 5 use cases, out of which 4 of the use cases are a mandatory, they are - Status Notification, Change Availability EVSE, Change Availability Charging Station and Lock Failure.

\subsection{Sending transaction related Meter values}

This functionality comes under Metering Functional block of OCPP 2.0. It describes the functionality that

Table 3. OCPP 2.0 Functionalities

\begin{tabular}{|c|c|}
\hline Functionality & Messages \\
\hline $\begin{array}{l}\text { Booting a Charging } \\
\text { Station }\end{array}$ & BootNotification \\
\hline $\begin{array}{l}\text { Configuring a } \\
\text { Charging Station }\end{array}$ & $\begin{array}{l}\text { Set Variables, Get Variables and } \\
\text { GetReportBase (respond } \\
\text { correctly to requests with } \\
\text { reportBase = } \\
\text { ConfigurationInventory, } \\
\text { FullInventory, Summary } \\
\text { Inventory). }\end{array}$ \\
\hline $\begin{array}{l}\text { Resetting a } \\
\text { Charging Station }\end{array}$ & Reset \\
\hline $\begin{array}{l}\text { Authorization } \\
\text { options }\end{array}$ & Authorize \\
\hline $\begin{array}{l}\text { Transaction } \\
\text { mechanism }\end{array}$ & Transaction Event \\
\hline Availability & $\begin{array}{l}\text { Only Change Availability and } \\
\text { Status Notification. }\end{array}$ \\
\hline Monitoring Events & $\begin{array}{l}\text { A basic implementation of the } \\
\text { Notify Event message to be used } \\
\text { to report operational state } \\
\text { changes and problem/error } \\
\text { conditions of the Charging } \\
\text { Station, e.g. for Lock Failure. } \\
\text { Also used for reporting built-in } \\
\text { monitoring events. }\end{array}$ \\
\hline $\begin{array}{l}\text { Sending transaction } \\
\text { related Meter values }\end{array}$ & Transaction Event \\
\hline DataTransfer & $\begin{array}{l}\text { Any OCPP implementations } \\
\text { should at least be able to reject } \\
\text { any request for Data Transfer if } \\
\text { no (special) functionality is } \\
\text { implemented. }\end{array}$ \\
\hline $\begin{array}{l}\text { Resetting a } \\
\text { Charging Station }\end{array}$ & Reset \\
\hline $\begin{array}{l}\text { Authorization } \\
\text { options }\end{array}$ & Authorize \\
\hline $\begin{array}{l}\text { Transaction } \\
\text { mechanism }\end{array}$ & Transaction Event \\
\hline
\end{tabular}


enables a Charging Station to send periodic, possibly clock-aligned Meter Values. Extensive metering data relating to transactions can be recorded and transmitted in different ways depending on its intended purpose. This Functional Block has 3 use cases in which Sending transaction related Meter Values is the MUST Use Case to Implement Basic OCPP 2.0.

\section{Sample Interface}

The OCPP protocol ensures the standardized communication between the Central Management System (CSMS) and the Charging Station. A user interface will make it convenient to for the users to work with this protocol running in the back-end. Figure II shows possible user interfaces, which can be used by the

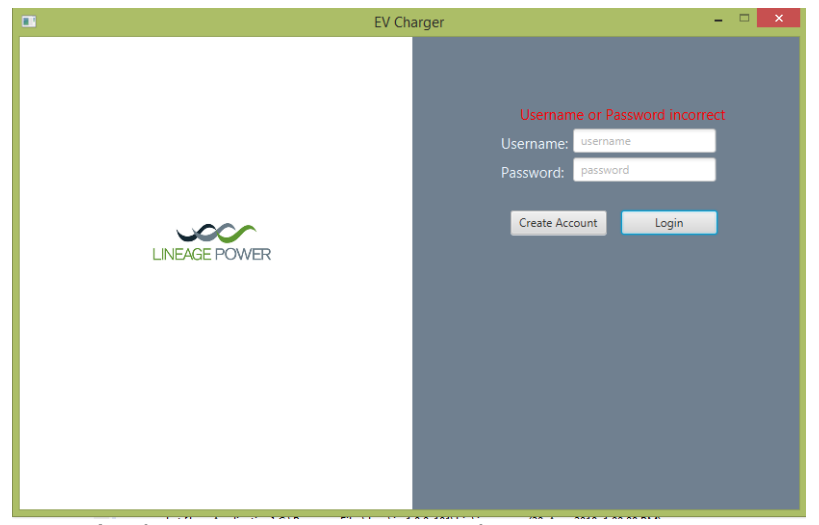

a) Administrator Login at Central Management System

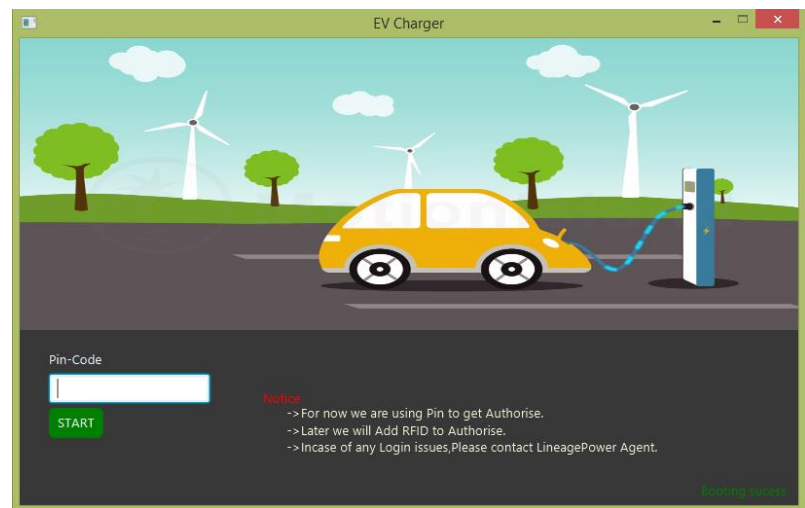

b) Login interface at Charging Station for the customer

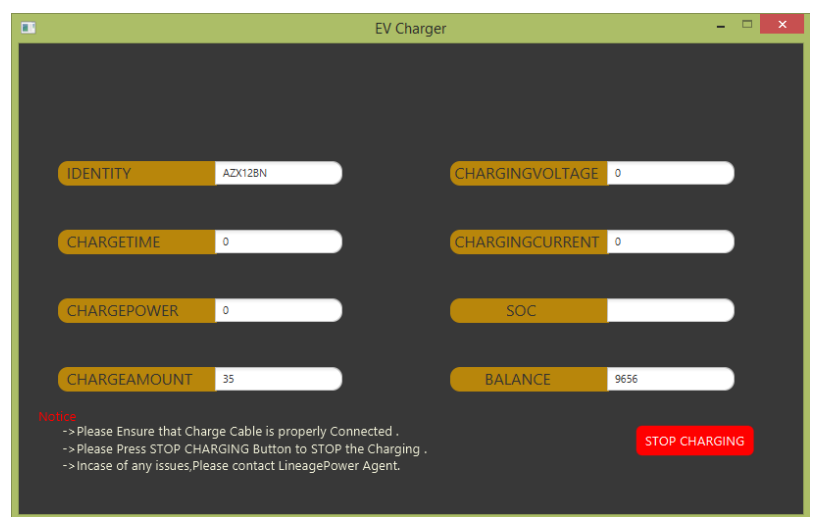

c) Status display while vehicle charging is in progress.

Fig. 2. Sample graphical user interface.
CSO in the CSMS and the consumer charge the electric vehicle at the charging station.

This sample implementation of the OCPP 2.0 protocol was developed using the Java programming language. Concepts like to object oriented programming and web sockets offered by the Java language makes it easy to implement the requirements of this protocol. The frontend design uses JavaFX to generate the graphical user interface (GUI).

\section{Conclusion}

This paper reviews the Open Charge Point Protocol (OCPP), which can be adopted as a standard for the back-end communication between electric vehicle charging stations and the central management system. The various versions of the protocol were discussed along with the improvements in its functionalities and features. Sample user interfaces of the possible implementation of the OCPP protocol were also shown for the central management system and the charging station, both.

\section{References}

1. D. Wellisch, J. Lenz, A. Faschingbauer, R. Pöschl, S. Kunze, IFAC-PapersOnLine (2015)

2. Open Charge Alliance - Global Platform For Open Protocols, https://www.openchargealliance.org/ (2018)

3. Committee Report on Standardization of Public EV Chargers,https://dhi.nic.in/writereaddata/UploadFil e/Standardization\%20of\%20protocol.pdf (2017)

4. Open Smart Charging Protocol 1.0, https://www.openchargealliance.org/protocols/ocpp $-10 /(2018)$

5. Open Charge Point Protocol 1.5, https://www.openchargealliance.org/protocols/ocpp $-15 /(2018)$

6. Open Charge Point Protocol 1.6, https://www.openchargealliance.org/protocols/ocpp -16/(2018)

7. Open Charge Point Protocol 2.0, https://www.openchargealliance.org/protocols/ocpp $-20 /(2018)$ 